\title{
The 3 Cs of Content, Context, and Concepts: A Practical Approach to Recording Unstructured Field Observations
}

\author{
Michael D. Fetters, MD, MPH, MA \\ Ellen B. Rubinstein, $P b D, M A^{2}$ \\ 'Mixed Methods Program, Department of \\ Family Medicine, University of Michigan \\ Medical School, Ann Arbor, Michigan \\ ${ }^{2}$ Department of Sociology and Anthro- \\ pology, North Dakota State University, \\ Fargo, North Dakota
}

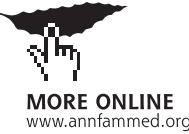

Conflicts of interest: authors report none.

\section{CORRESPONDING AUTHOR}

Michael D. Fetters, MD, MPH, MA Mixed Methods Program and Department of Family Medicine

University of Michigan Medical School 1018 Fuller St

Ann Arbor, MI 48104-1213

mfetters@med.umich.edu

\begin{abstract}
Most primary care researchers lack a practical approach for including field observations in their studies, even though observations can offer important qualitative insights and provide a mechanism for documenting behaviors, events, and unexpected occurrences. We present an overview of unstructured field observations as a qualitative research method for analyzing material surroundings and social interactions. We then detail a practical approach to collecting and recording observational data through a "3 Cs" template of content, context, and concepts. To demonstrate how this method works in practice, we provide an example of a completed template and discuss the analytical approach used during a study on informed consent for research participation in the primary care setting of Qatar.
\end{abstract}

Ann Fam Med 2019;17:554-560. https://doi.org/10.1370/afm.2453.

\section{INTRODUCTION}

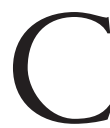
linical observation is a method well known to primary care physicians. It is the rare physician who takes a patient's words at face value without also using contextual clues, such as the patient's appearance and behavior, to construct a picture of the patient's health. ${ }^{1}$ Indeed, medical education has recently highlighted the need for physicians to be more observant through innovative curricula that teach observational skills by examining art. ${ }^{2,3}$

Field observations offer insight into behaviors and the environment ${ }^{4}$ and can play an important role in primary care research. A decades-long history of observational research in primary care has demonstrated how contextual factors both in and out of the clinic influence the effectiveness of interventions, as well as clinical outcomes. ${ }^{5-9} \mathrm{~A}$ recent commentary in JAMA Internal Medicine has called for more "ethnographic and field studies" to capitalize on the "value of direct observation," particularly in studies of patient safety. ${ }^{10(\mathrm{p} 1024)}$

Unfortunately, most primary care researchers lack a practical approach for including field observations in their studies. Here, we present an overview of unstructured field observations as a qualitative research method for analyzing material surroundings and social interactions, aimed at researchers new to unstructured observations. We then detail a practical approach to collecting and recording observational data through a "3 Cs" template of content, context, and concepts. To demonstrate how this method works in practice, we provide an example of a completed template and discuss the analytical approach used during a study on informed consent for research participation in the primary care setting of Qatar.

\section{BACKGROUND}

Observational field research has its roots in the social sciences and is most often associated with participant observation fieldwork in cultural anthropology and sociology, though it has spread to disciplines as diverse as nursing, education, and social work. ${ }^{11}$ Although he was not the first to 
undertake fieldwork, the Polish anthropologist Bronislaw Malinowski has been ascribed with popularizing participant observation as a research method. ${ }^{12}$ Unlike structured interview sessions, participant observation allows for more flexible interactions with research participants through social events, casual conversations, and semistructured interviews conducted in settings that are a natural part of participants' everyday lives. ${ }^{13}$ There is some debate as to how much a researcher should "participate" in daily activities, ${ }^{12}$ but it is often enough simply "to be tolerated as an unobtrusive observer."14(p195)

Malinowski's work was influenced by the scientific positivism of the era, but later social scientists launched an antipositivist (interpretivist) critique that shifted the focus of observational research from a search for social facts to an understanding of cultural meanings. ${ }^{15}$ We follow an interpretivist approach in believing the purpose of observational research is to arrive at what the anthropologist Clifford Geertz called "thick description."16 In a famous example, Geertz explains how the same action (a quick blink of the right eye) holds different meanings based on the cultural context in which it occurs. ${ }^{16}$ Only in a specific context will a blink be recognized as a wink-a conspiratorial signal to a friend-rather than as a meaningless twitch of the eye. Thick description, then, uses empirical data from multiple sources to contextualize individual behavior and interpret its meaning.

A crucial assumption in participant observation is that the researcher is the instrument of data collection. ${ }^{17}$ This assumption means all data are filtered through the researcher, through his or her personal characteristics, background, and experiences. ${ }^{18}$ The result is a different relationship to objectivity than that found in the natural sciences. Observational research does not seek objectivity through a conceptual separation between researcher and study participants and phenomena. ${ }^{19}$ Researchers are not blank slates; instead, they use prior knowledge and experiences as either implicit or explicit bases of comparison to understand what they observe in the field. ${ }^{20}$ Personal bias is not seen as a flaw but as part of data collection. ${ }^{12}$ Qualitative researchers speak of using bias to explore hunches or ideas, as well as to seek out information contrary to their own views. ${ }^{21}$ It is critical before going into the field for researchers to conduct a personal inventory and reflect on their preconceptions, as these will affect their interpretation of events. ${ }^{21}$ Researchers must also remain aware of potential differences in status between themselves and their study participants, where higher status may be conferred by socioeconomic, educational, occupational, or other types of privilege, or some combination thereof. ${ }^{19}$ Such differences create a certain power dynamic between researchers and participants that can influence data collection. ${ }^{19} \mathrm{~A}$ reflective activity, such as journaling or freewriting, can help define the researcher's lens and help the researcher recognize how he or she may be perceived in the field. ${ }^{22}$

\section{RATIONALE FOR COLLECTING FIELD OBSERVATIONS}

Perhaps the most compelling reason for conducting observations is to understand behavior (Table 1). Studies have suggested that nonverbal behavior plays a considerable role in communicating shared cultural meanings. ${ }^{23}$ Furthermore, emotions are communicated more through facial expression and vocal tone and inflection than through spoken word. ${ }^{24,25}$ Finally, as it pertains to health research, individuals tend to underreport their unhealthy or socially undesirable behaviors ${ }^{26,27}$ and overreport the converse. ${ }^{28}$ Observational research thus contributes to understanding human behavior in all of these scenarios.

Field observations can help researchers understand how the interactions and activities in a given setting inform behaviors and beliefs (Table 1). ${ }^{29}$ They contribute to uncovering the broader context of a given scenario, making observational research especially well suited for studying process. ${ }^{19}$ In primary care, for example, observational research has deepened understanding of the clinical contexts in which practice transformation to patient-centered medical homes has occurred. ${ }^{30-36}$ Field observations have also helped contextualize the (quantitative) results of randomized controlled trials, by providing insight into why certain
Table 1. Reasons for Conducting Observations in Primary Care Research, With Clinical Examples

\begin{tabular}{cc}
\hline Reasons to Observe & Clinical Examples \\
\hline To understand behavior & $\begin{array}{r}\text { Describe whether or how staff follow clinical } \\
\text { guidelines or study protocols }\end{array}$ \\
To understand context & $\begin{array}{c}\text { Understand environmental factors influencing } \\
\text { uptake of an intervention } \\
\text { Examine at baseline how clinical preventive ser- } \\
\text { vices are delivered in offices }\end{array}$ \\
To understand process & $\begin{array}{c}\text { Examine variations in how clinical preventive ser- } \\
\text { vices are implemented across multiple practices }\end{array}$ \\
$\begin{array}{c}\text { To see what people are } \\
\text { reluctant to discuss }\end{array}$ & $\begin{array}{c}\text { Identify perceived cultural taboos, for example, } \\
\text { parents reluctant to discuss HPV vaccination for } \\
\text { prepubertal children } \\
\text { To gain direct personal } \\
\text { experience and } \\
\text { knowledge }\end{array}$ \\
$\begin{array}{c}\text { Explore patient experiences of undergoing clinical } \\
\text { procedures, for example, the experience of colo- } \\
\text { noscopy preparation } \\
\text { selected perceptions }\end{array}$ & $\begin{array}{c}\text { Observe how patients respond to universal screen- } \\
\text { ing questions, for example, depression screen- } \\
\text { ing, intimate personal violence screening }\end{array}$ \\
\hline HPV = human papillomavirus. &
\end{tabular}


randomized controlled trials have succeeded or failed. ${ }^{9,37}$

Thus, field observations allow researchers to move beyond selected perceptions and protocols, and better understand the nature of particular activities, who performs them, and the contexts in which they occur.

Observational research may not always be appropriate, and under certain circumstances, participants will not tolerate an observer (Table 2). Individuals who engage in socially undesirable or illegal behavior may be reluctant to have an observer present or be at risk personally ${ }^{12}$ (although the opposite might also be true ${ }^{38}$ ). Sometimes the presence of an observer might change participants' behavior, a phenomenon known as the Hawthorne effect. ${ }^{39}$ Research has shown this effect may not be as great as feared ${ }^{40}$ however, and multiple observations over the long term can be a mitigating factor. ${ }^{29}$

\section{UNSTRUCTURED AND STRUCTURED FIELD OBSERVATIONS}

A central tenet of observational research is that observations must be recorded to count as data, ${ }^{12}$ and it is only through the regular and systematic recording of field observations that researchers create texts for subsequent analysis. ${ }^{41}$ Field observations can be structured, unstructured, or a combination of both. Structured observations use a template to record tabulations of specific behaviors that can be measured and analyzed statistically. ${ }^{42}$ These observations often focus on highly specific issues and are indicated when the intent is to validly and reliably measure specific behaviors. Unstructured observational data use the researcher's words for thick description of phenomena or events. These words emerge through the researcher's experience in the field. ${ }^{43}$ Even though unstructured, the observations are still focused because they address a research question or specific phenomenon. Within that focus, there is great latitude in what the researcher can choose to record (Table 3).

To illustrate the potential of field observations, we introduce a study that relied heavily on observational data supplemented by interviews. The first author (M.D.F.) served as co-principal investigator on a multistage, mixed methods parent study in Qatar to develop a health care quality assessment instrument that was adapted for populations whose native languages were Arabic, English, Hindi, and Urdu. ${ }^{44} \mathrm{~A}$ theoretical model, Cultural Construction of Clinical Reality developed by Kleinman et al ${ }_{1}^{45}$ guided the research. During the first stage of qualitative data collection, Qatari team members expressed concern about how potential participants would respond to recruitment strategies dictated by US-based institutional review boards. Existing literature had little guidance for recruiting participants in Arabian Gulf countries. We therefore conducted a study to explore how individuals in Qatar responded to in-person recruitment requests. ${ }^{46}$ The 3 Cs template emerged from the need for institutional review board approval of data collection instruments and as a training instrument for research assistants.

\section{THE 3 CS UNSTRUCTURED FIELD OBSERVATIONS TEMPLATE}

The 3 Cs template provides an easy approach to collecting observational data. A full 3 Cs template (Supplemental Appendix 1, available at http://www.AnnFamMed. org/content/17/6/554/suppl/DC1/) includes the study metadata (details about the project), the research question, and the $3 \mathrm{Cs}$ of context, content, and concepts.

\section{Field Observation Metadata}

The study metadata include information such as the project title, the study document type, the observer, the date and time, the location, and a participant description (eg, ID, descriptor if multiple individuals). The metadata from a single observation collected during the Qatar recruitment study are given in Supplemental Appendix 2, available at http://www. AnnFamMed.org/content/17/6/554/suppl/DC1/. Additional information here included the language spoken by the researcher and participant.

\section{Research Question}

The research question keeps observations focused on the purpose of the study. Because there is bound to be 
Table 3. The $3 \mathrm{Cs}-$ Context, Content, and Concepts-Approach to Field Observations

\begin{tabular}{|c|c|c|}
\hline Category & Definition & Focus \\
\hline Context & $\begin{array}{l}\text { The circumstances (both material and theoreti- } \\
\text { cal) under which observations are being con- } \\
\text { ducted, as well as any historical, sociocultural, } \\
\text { political, and other information that may } \\
\text { directly (or indirectly) influence data collection }\end{array}$ & $\begin{array}{l}\text { Who is there as observer? } \\
\text { What is your reason for being there? } \\
\text { Why this location? } \\
\text { What is your state of mind (eg, confused, unhappy, tired, excited)? } \\
\text { What are your key areas of (observational) interest based on your prior } \\
\text { research experience and/or scholarly background? }\end{array}$ \\
\hline Content & The matter or substance of what happened & $\begin{array}{l}\text { Who are the participants? How are they related, if at all (eg, physicians and } \\
\text { patients, work colleagues, friends or family members, cancer survivors)? } \\
\text { How do participants interact? } \\
\text { What actions/events are occurring? } \\
\text { What is the timing/sequence of events? } \\
\text { What quotes best capture the exchange that occurred? }\end{array}$ \\
\hline
\end{tabular}

individual variation in data collection (recalling that the researcher is the instrument of data collection), including the question on the template provides a focal point for recording details. As illustrated in Supplemental Appendix 2, there were both primary and secondary research questions for researchers to address.

\section{Context, Content, and Concepts}

The context, content, and concepts are summarized in Table 3 and explained in further detail below.

\section{Context}

The first C, context, has a dual meaning: its most immediate referent is the circumstances in which the researcher is making observations (eg, who is doing the observation, where, and when). In a broader sense, context also refers to the researcher's (or team's) prior research experience, and could include knowledge gained from reading the scholarly literature, and additional information about a population, organization, or community-anything that speaks to the social surroundings and recent events that may influence the present interaction. ${ }^{47}$ Context can act as a reminder of the researcher's purpose in using observational methods - and may also include information about the researcher's introduction to the field (eg, "invited by Dr A to observe her clinic" or "clinic recruited through practice manager"). Visuals, including sketches or photographs (if possible), may be useful, especially if certain structural features stand out (eg, small vs large waiting room; front staff behind an open desk vs behind a glass partition). This information can enable quick and easy comparisons between multiple locations.

\section{Content}

The second C, content, is more focused than context, as it refers directly to what happens during the observation period. (We recommend that researchers record each observation period on a separate template, creating multiple shorter documents, for each episode of observing, rather than in a single long document, for later analysis.) Although observational research is often touted as holistic - that is, covering everything within the 5 senses during a given stretch of time-in truth, researchers continually make decisions about where to point their focus. The research question and the project's theoretical orientation (the research questions, and the first $\mathrm{C}$, context, described previously) are paramount here in guiding the observations.

\section{Concepts}

The third C, concepts, is a space for the researcher to connect the minutiae of his or her field observations with the bigger picture, to think back to the research question or hypothesis and compare theory with practice. It can be used to reflect about the process of research, or procedural or ethical questions that arise in the field. It is a space for nascent analysis, where the researcher can try out new ideas based on insights gained in the field. Researchers may take note of emergent patterns or themes (as in grounded theory ${ }^{48}$ ), may 
reflect on their experience in the field, or both. In this way, the third $\mathrm{C}$ provides a sort of running commentary on the field observations, which serves both as the foundation for later analysis and as an audit trail that demonstrates how observation, data collection, theory, and analysis are all intertwined. ${ }^{15}$

\section{USING THE 3 CS APPROACH IN THE FIELD Recording Field Jottings}

There is never enough time in the field to write down everything one observes. Indeed, recording observations becomes even more difficult when the researcher participates in ongoing activities by, for example, engaging in conversation, directing a lost patient to the exit, or lending a hand to set up for a meeting. Furthermore, most of the time, a field researcher does not bring a computer into the field but rather relies on pen and paper, the latter being less obtrusive and easier to manage (although that has changed with the advent of smartphones and tablets). Generally speaking, therefore, no one writes actual field notes in the field. Rather, they capture field jottings - words, phrases, or drawings to jog their memories after the fact. ${ }^{41}$ In the Qatar recruitment study, ${ }^{46}$ the research assistants used a printed 3 Cs template for jotting down ideas as they occurred.

\section{Expanding on Field Jottings}

After leaving the field site, the observer has the opportunity to construct, from field jottings, a more extensive record of what was observed. ${ }^{29}$ It is important to write these expanded field notes as soon as possible after the observation session (hours, not days, later), the more time that passes, the greater chance that the researcher will recall fewer details. A first pass should focus on writing descriptive text focusing on the "what" and "how" while avoiding summative or generalizing statements. The best field notes are rich with details that convey a sense of what it is like to be in the time and space described (ie, thick description). Expanded and edited notes can be found in Supplemental Appendix 2.

\section{Working With a Research Team and Analyzing the Data}

Primary care research is typically team based. The 3 Cs approach to field observations can facilitate iterative data collection and analysis. Field notes should be shared among team members both to encourage the entire team's familiarity with the field and to identify salient points for future data collection and pattern recognition. The first few observational sessions should be the most detailed, as this is when the researcher is least familiar with the field. ${ }^{15}$ Of course, not all details will ultimately prove relevant, but they can act as a starting point for more refined observations later on. Furthermore, after the researcher begins to recognize what counts as the norm in a given setting, he or she can then more easily identify deviations from that norm. Such surprises in the field can lead to unexpected insights that generate new directions for future research.

Field notes can be analyzed like any other qualitative text by, for example, searching for key words and coding for thematic content. Even if they are not formally analyzed, field notes may provide important context for understanding data derived from (timelimited) interviews and surveys. In the Qatar recruitment study ${ }_{1}{ }^{46}$ the team conducted iterative analysis of the textual data from field observations and interviews, which led to the creation of a coding scheme in Atlas. ti (ATLAS.ti Scientific Software Development GmbH). The team also integrated numerical data from the demographic instrument and recruitment procedures, to create a narrative format for the results.

\section{Finishing Field Observations in a Study}

A final consideration is when to end the observational period or series. One possibility is to have a predetermined end point. In the Qatar recruitment study, ${ }_{1}{ }^{46}$ field observations continued until the study recruitment goals were met. An alternative is to seek data saturation. Guidelines for determining the saturation point in qualitative research vary, although a recent review calls for saturation to be operationalized in terms of research question(s), theoretical framework, and analytical goals. ${ }^{49}$

\section{DISCUSSION}

Field observations are paramount in understanding contextual factors in any research project and have the potential to reveal important insights about the way actors and institutions work in a given place and time. Observational research is inductive and iterative, ${ }^{15}$ and its greatest strength is its open-endedness. Because the researcher does not work in a controlled environment or with a standardized checklist or questionnaire, he or she is able to capture any data that do not fit into a priori categories. In such a setting, the research question serves as a guide, not a mandate, and it leaves room to address unexpected occurrences.

Although the 3 Cs template provides an excellent entrée for the use of field observations, there are other observational alternatives. Structured observations may be better indicated for inquiry exploring systematically the nature and metrics of phenomena, with integration across multiple observers for the purpose of statistical analysis. Another option is video recording, which 
yields multiple data sources, such as verbal, paraverbal, and nonverbal responses, and requires specific levels of skills and techniques for analysis. ${ }^{50}$

The 3 Cs approach to unstructured field observations can be used when observation is the primary research method ${ }^{46}$ or in tandem with another research method, such as qualitative interviews. ${ }^{51}$ In the Qatar recruitment study, the observations were conducted more with the intent of being supplemental, but ultimately served as the primary source for a specific publication. ${ }^{46}$ The template, which can be submitted for institutional review board approval, provides a straightforward mechanism for recording events and behaviors in almost any project involving human participants. As mixed methods gain increasing popularity in health services research, ${ }^{52}$ unstructured field observations can play an important role in contextualizing other types of qualitative and quantitative data, resulting in more rigorous research designs and data collection.

\section{To read or post commentaries in response to this article, see it online at http://www.AnnFamMed.org/content/17/6/554.}

Submitted November 4, 2018; submitted, revised, April 12, 2019; accepted May 7, 2019.

Key words: primary care; family medicine; general medicine; research methodology; qualitative research; mixed methods: participatory/action research; field observations; field notes; Hawthorne effect; communication; behavioral research; informed consent

Previous presentations: Portions of the content of this article were presented at the 2012 North American Primary Care Research Group (NAPCRG) Annual Meeting; December 1-5, 2012; New Orleans, Louisiana; and at the 2013 NAPCRG Annual Meeting; November 9-13, 2013; Ottawa, Canada.

Supplemental Materials: Available at http://www.AnnFamMed. org/content/17/6/554/suppl/DC1/.

\section{References}

1. Mast MS. On the importance of nonverbal communication in the physician-patient interaction. Patient Educ Couns. 2007;67(3):315-318.

2. Bardes CL, Gillers D, Herman AE. Learning to look: developing clinical observational skills at an art museum. Med Educ. 2001;35(12): 1157-1161.

3. Schaff PB, Isken S, Tager RM. From contemporary art to core clinical skills: observation, interpretation, and meaning-making in a complex environment. Acad Med. 2011;86(10):1272-1276.

4. Sanjek R. Fieldnotes: The Makings of Anthropology. Ithaca, NY: Cornell University Press; 1990.

5. Bauer MS, Damschroder L, Hagedorn H, Smith J, Kilbourne AM. An introduction to implementation science for the non-specialist. BMC Psychol. 2015;3(1):32.

6. Crabtree BF, Miller WL, Stange KC. Understanding practice from the ground up. J Fam Pract. 2001;50(10):881-887.

7. Crosson JC, Stroebel C, Scott JG, Stello B, Crabtree BF. Implementing an electronic medical record in a family medicine practice: communication, decision making, and conflict. Ann Fam Med. 2005; 3(4):307-311.
8. Howard J, Shaw EK, Clark E, Crabtree BF. Up close and (inter) personal: insights from a primary care practice's efforts to improve office relationships over time, 2003-2009. Qual Manag Health Care. 2011;20(1):49-61.

9. Shaw EK, Ohman-Strickland PA, Piasecki A, et al. Effects of facilitated team meetings and learning collaboratives on colorectal cancer screening rates in primary care practices: a cluster randomized trial. Ann Fam Med. 2013;11(3):220-228, S1-S8.

10. Horwitz Ll. The importance of user-centered design and evaluation: Systems-level solutions to sharp-end problems. JAMA Intern Med. 2018;178(8):1023-1024.

11. Kawulich BB. Participant Observation as a Data Collection Method. Forum: Qualitative Social Research. 2005;6(2); art 43.

12. Musante (DeWalt) K. Participant observation. In: Bernard HR, Gravlee CC, eds. Handbook of Methods in Cultural Anthropology. Lanham, MD: Rowland \& Littlefield; 2014:251-292.

13. Agar MH. Speaking of Ethnography. Beverly Hills, CA: Sage Publications; 1986

14. Rossman GB, Rallis SF. Learning in the Field: An Introduction to Qualitative Research. 2nd ed. Thousand Oaks, CA: Sage Publications; 2003.

15. O'Reilly K. Key Concepts in Ethnography. London, UK: Sage Publications; 2009.

16. Geertz C. Thick description: toward an interpretive theory of culture. In: Interpretation of Cultures: Selected Essays. New York, NY: Basic Books; 2000:3-30.

17. Willms DG, Johnson NA. Essentials in Qualitative Research: A Notebook for the Field. Hamilton, Ontario, Canada: McMaster University; 1993.

18. Malterud K. Qualitative research: standards, challenges, and guidelines. Lancet. 2001;358(9280):483-488.

19. LeCompte MD, Schensul JJ. Designing and Conducting Ethnographic Research: An Introduction. 2nd ed. Lanham, MD: AltaMira Press; 2010.

20. Gay y Blasco P, Wardle H. How to Read Ethnography. New York, NY: Routledge; 2007.

21. Finlay L, Gough B, eds. Reflexivity: A Practical Guide for Researchers in Health and Social Sciences. Oxford, UK: Blackwell Sciences Ltd; 2003.

22. Ortlipp M. Keeping and using reflective journals in the qualitative research process. Qual Rep. 2008;13(4):695-705.

23. Knapp ML, Hall JA, Horgan TG. Nonverbal Communication in Human Interaction. 8th ed. Boston, MA: Wadsworth, Cengage Learning; 2014.

24. Mehrabian A, Ferris SR. Inference of attitudes from nonverbal communication in two channels. J Consult Psychol. 1967;31(3):248-252.

25. Mehrabian A. Nonverbal Communication. New Brunswick, NJ: Aldine Transaction; 1972.

26. Latkin CA, Edwards C, Davey-Rothwell MA, Tobin KE. The relationship between social desirability bias and self-reports of health, substance use, and social network factors among urban substance users in Baltimore, Maryland. Addict Behav. 2017;73:133-136.

27. Widmar NJO, Byrd ES, Dominick SR, Wolf CA, Acharya L. Social desirability bias in reporting of holiday season healthfulness. Prev Med Rep. 2016;4:270-276.

28. Contzen N, De Pasquale S, Mosler H-J. Over-reporting in handwashing self-reports: potential explanatory factors and alternative measurements. PLoS One. 2015;10(8):e0136445-e0136445.

29. Bogdewic SP. Participant observation. In: Crabtree BF, Miller WL, eds. Doing Qualitative Research. 2nd ed. Thousand Oaks, CA: Sage Publications; 1999:47-69.

30. Nutting PA, Miller WL, Crabtree BF, Jaen CR, Stewart EE, Stange KC. Initial lessons from the first national demonstration project on practice transformation to a patient-centered medical home. Ann Fam Med. 2009;7(3):254-260. 
31. Jaén CR, Crabtree BF, Palmer RF, et al. Methods for evaluating practice change toward a patient-centered medical home. Ann Fam Med. 2010;8 Suppl 1:S9-S20; S92.

32. Nutting PA, Crabtree BF, Miller WL, Stewart EE, Stange KC, Jaen CR. Journey to the patient-centered medical home: a qualitative analysis of the experiences of practices in the National Demonstration Project. Ann Fam Med. 2010;8 Suppl 1:S45-S56; S92.

33. Crabtree BF, Nutting PA, Miller WL, et al. Primary care practice transformation is hard work: insights from a 15-year developmental program of research. Med Care. 2011;49(Suppl):S28-S35.

34. Wise CG, Alexander JA, Green LA, Cohen GR, Koster CR. Journey toward a patient-centered medical home: readiness for change in primary care practices. Milbank Q. 2011;89(3):399-424.

35. Goldman R, Borkan J. Anthropological Approaches: Uncovering Unexpected Insights about the Implementation and Outcomes of PatientCentered Medical Home Models. Rockville, MD: Agency for Healthcare Research and Quality; 2013.

36. True G, Butler AE, Lamparska BG, et al. Open access in the patientcentered medical home: lessons from the Veterans Health Administration. J Gen Intern Med. 2013;28(4):539-545.

37. van der Straten A, Stadler J, Luecke E, Laborde N, Hartmann M, Montgomery ET; VOICE-C Study Team. Perspectives on use of oral and vaginal antiretrovirals for HIV prevention: the VOICE-C qualitative study in Johannesburg, South Africa. J Int AIDS Soc. 2014;17(3 Suppl 2):19146.

38. Bourgois PI. In Search of Respect: Selling Crack in El Barrio. Cambridge, UK: Cambridge University Press; 1995.

39. Salkind NJ. Hawthorne effect. In: Salkind NJ, ed. Encyclopedia of Research Design. Thousand Oaks, CA: Sage Publications; 2010.

40. Kurtz SL. Measuring and accounting for the Hawthorne effect during a direct overt observational study of intensive care unit nurses. Am J Infect Control. 2017;45(9):995-1000.

41. Emerson RM, Fretz RI, Shaw LL. Writing Ethnographic Fieldnotes. 2nd ed. Chicago, IL: University of Chicago Press; 2011.
42. Callahan EJ, Bertakis KD. Development and validation of the Davis Observation Code. Fam Med. 1991;23(1):19-24.

43. Mulhall A. In the field: notes on observation in qualitative research. J Adv Nurs. 2003;41(3):306-313.

44. Hammoud MM, Elnashar M, Abdelrahim H, et al. Challenges and opportunities of US and Arab collaborations in health services research: a case study from Qatar. Glob J Health Sci. 2012;4(6): 148-159.

45. Kleinman A, Eisenberg L, Good B. Culture, illness, and care: clinical lessons from anthropologic and cross-cultural research. Ann Intern Med. 1978;88(2):251-258.

46. Killawi A, Khidir A, Elnashar M, et al. Procedures of recruiting, obtaining informed consent, and compensating research participants in Qatar: findings from a qualitative investigation. BMC Med Ethics. 2014;15:9.

47. Phillippi J, Lauderdale J. A guide to field notes for qualitative research: context and conversation. Qual Health Res. 2018;28(3): 381-388.

48. Charmaz K. Grounded theory. In: Smith JA, Harré R, Van Langenhove L, eds. Rethinking Methods in Psychology. London, UK: Sage Publications; 1995:27-49.

49. Saunders B, Sim J, Kingstone T, et al. Saturation in qualitative research: exploring its conceptualization and operationalization. Qual Quant. 2018;52(4):1893-1907.

50. Henry SG, Fuhrel-Forbis A, Rogers MA, Eggly S. Association between nonverbal communication during clinical interactions and outcomes: a systematic review and meta-analysis. Patient Educ Couns. 2012;86(3):297-315.

51. Khidir A, Asad H, Abdelrahim H, et al. Patient responses to research recruitment and follow-up surveys: findings from a diverse multicultural health care setting in Qatar. BMC Med Res Methodol. 2016;16:10.

52. Plano Clark VL. The adoption and practice of mixed methods: U.S trends in federally funded health-related research. Qual Inq. 2010; $16(6): 428-440$. 